\title{
Cartesian analysis: A computer-video interface for measuring motion without physical contact
}

\author{
PALMER MORREL-SAMUELS \\ Kewalo Basin Laboratory, University of Hawaii, Honolulu, Hawaii \\ and \\ ROBERT M. KRAUSS \\ Columbia University, New York, New York
}

\begin{abstract}
In this paper, we describe a computer-video interface capable of measuring videotaped motion without physical contact. It constructs imaginary $x$-, $y$-, $z$-coordinates around a moving object by juxtaposing front and side views on one video record. A special effects generator (SEG) superimposes this two-part image onto the microcomputer's graphic output. The user watches the SEG's output and traces the motion of interest in real-time with a computer-generated cursor, a process that assesses the onset time, termination time, duration, linear displacement (i.e., length), and velocity of each traced movement. Reliability coefficients between two independent users were .99 for onset time, .85 for duration, .89 for displacement, and .90 for velocity. In 80 gestures, the correlation between estimated displacement and measured displacement was .73; the correlation between estimated duration (determined from frame-by-frame inspection of the videotape) and measured duration was .80 . Twenty-five measurements of displacement for a motorized target traveling 75.4 in. differed from the true value by $|.06|,|.06|$, and $|.30|$ in. for the $x, y$, and $z$ dimensions, respectively.
\end{abstract}

Studies of human motion can be found throughout the social sciences and in virtually every branch of experimental psychology, but much of this research has been impeded by the fact that body motion is often ephemeral and nondescript. These qualities have led to a proliferation of methods requiring nominal categorization (see, e.g., Ekman \& Friesen, 1972; Hutchinson, 1970; Laban, 1974) or estimation of angles, linear displacement (i.e., total length of travel through all planes), and duration (see, e.g., Eshkol \& Wachmann, 1958; Munteanu \& Latcu, 1971). However, the reliability and validity of such methods is open to question (Morrel-Samuels, 1980): Estimations of linear displacement, though relatively accurate when averaged across subjects for targets of moderate size and velocity (Bradley \& Godiksen, 1984), do vary as a function of the viewer's gender (Sholl, 1989), experience (Cavallo \& Laurent, 1988) and the mean of his or her recent length estimations (Morris \& Rule, 1988); estimations of angle (Thomas \& Jamison, 1975), velocity (Cavallo \& Laurent, 1988), and duration (Beck, 1988; Nakajima, Nishimura, \& Teranishi, 1988) show similar

This work is based on the PhD dissertation of Palmer Morrel-Samuels. It was supported by a Biomedical Grant from Columbia University, and by Grant BNS-8616131 from the National Science Foundation to Robert M. Krauss. We would like to thank Julian Hochberg and Walter Mischel for their valuable help throughout the project. The consistent dedication of Chris Colasante and Janna Stubblefield was also greatly appreciated. A copy of the code is available on request by writing to Palmer Morrel-Samuels at Kewalo Basin Lab, University of Hawaii, 1129 Ala Moana Blvd., Honolulu, HI 96814 (BITNET: T846680@ UHCCMVS). susceptibility to error. Moreover, determining what does and does not constitute a discrete movement is itself subject to extraneous influences. For example, viewers typically report seeing more discrete action units after repeated viewings (Buck, Baron, \& Barrette, 1982; Newtson, Engquist, \& Bois, 1977), after viewing an unexpected action (Newtson, 1973), and when they believe the viewed actions are intentional (Atkinson \& Allen, 1983).

Recently, computer-assisted methods for measuring motion have become available (Futrelle \& Potel, 1975; Poizner, Wooten, \& Salot, 1986). Most of them require neither estimation nor nominal taxonomies and are used in studies of gesture (e.g., Poizner, Klima, Bellugi, \& Livingston, 1986) and limb motion (Dowd \& Tronick, 1986) to furnish quantitative measurements of displacement, location, duration, and so forth. Typically such methods involve either optical projection of a subject's motion onto a digitizing tablet (Potel \& Sayre, 1976; Potel, Sayre, \& Robertson, 1979) or other mechanical means (e.g., a half-silvered mirror) of superimposing the image of a computer screen and the motion of interest (Barnes, Vaughan, Jorgensen, \& Rosenbaum, 1989). Some involve a degree of physical contact, with subjects being required to wear LEDs on limbs and joints (see, e.g., Poizner, Wooten, \& Salot, 1986; this is also the case with the Selspot Movement Monitoring System). ${ }^{I}$ These computer-assisted methods operate by constructing a virtual $x, y, z$ space around the subject. In all such methods involving recorded footage-excluding ones that rely on estimation to provide $z$-axis information (such as those of Diersen, Lorenc, \& Spiraleri, 1961; Pearson, McGin- 
ley, \& Butzel, 1963; Swanson \& Taylor, 1982; Trochim, 1976) or ignore the third dimension entirely (e.g., that of Jouen \& Lepecq, 1989)-two simultaneous views are provided of 1 subject, through the use of either a mirror or an additional camera (Dapena, 1978; Hofsten, 1979 , 1980; Mackay, Potel, \& Rubin, 1982). In all twoperspective methods for videotape, frame-by-frame analysis is used to digitize the point of interest in each frame (e.g., Peak 3D Motion Measurement Module) ${ }^{2}$ Because none runs in real-time, it is often impractical to analyze a videotaped experimental corpus in its entirety, a fact that has limited the scope of several recent studies (e.g., Dowd \& Tronick, 1986).

In the present method, we use a computer-video interface that is inexpensive and requires neither frame-byframe analysis nor physical contact with the subject's body. It incorporates two phases of operation, each of which places the system's components in a different configuration. During the first phase, the moving subject is recorded on videotape. During the second phase, these videotapes are viewed on the system's screen and the location of a moving body-part is traced with a computergenerated cursor. Because the computer stores the momentary location of the cursor in memory, the system can provide $x-, y-, z$-coordinates for any point in the field of view and can furnish precise measurements for any visible movement. In its first test, Cartesian analysis was used to measure the hand gestures that accompany spontaneous speech; the system furnished data on gesture duration, velocity, and linear displacement, so that the relation between speech, gesture meaning, and gesture form could be examined (Morrel-Samuels, 1989).

\section{METHOD}

Thirteen photographic slides (showing landscapes, buildings, people, etc.) were projected onto a screen in random order to 17 subjects from Columbia University's subject pool. Each slide was shown for $70 \mathrm{sec}$, and the subjects were instructed to describe what they saw throughout that period to a confederate seated nearby.

\section{Procedure and Apparatus}

Recording hand motion. During their narratives, the subjects were videotaped from the front and side by two cameras. The cameras fed their signals to a special effects generator (SEG), which synchronized the two signals and juxtaposed the images so that both views appeared side-by-side on the same monitor. This composite picture was recorded by a videocassette recorder (VCR) interfaced with a microcomputer; the interface ran from the I/O port of the microcomputer to the VCR's audio input, and enabled the microcomputer's annunciator to place a brief $+.5-\mathrm{V}$ spike on one of the audio channels of the videotape. The subject's speech was recorded on the second audio channel.

Equipment consisted of two video cameras with genlock capability (Panasonic Model WV240P) positioned

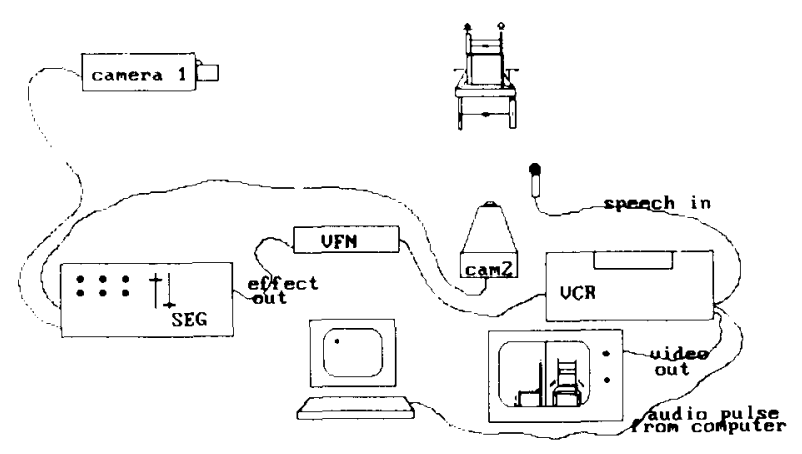

Figure 1. Equipment configuration for recording motion.

on perpendicular axes $18 \mathrm{ft}$ from the subject, a low impedance cardioid microphone (Beyer Dynamic), an SEG with internal sync generator (Panasonic Model WJ-540A), a Umatic format VCR (Sony VO-2800), a monochrome video monitor (Sony Model 19-4), and a 64K microcomputer (Apple II+). A frame number generator (VFN; Berkeley Viatronics) placed an incrementing visible number on each video frame, so that frame-by-frame inspection of the videotape would be possible if the need arose. Software to create the $+.5-\mathrm{V}$ spike was an optimized BASIC program (SIGNAL MAKER) written for this system and based on another, similar interface (Krauss, MorrelSamuels, \& Hochberg, 1988). A schematic drawing of the equipment configuration is shown in Figure 1.

Ascertaining measurements. To measure subjects' hand movements, the equipment was connected (see Figure 2) so that the SEG superimposed the original video footage with the image from a video camera focused on the screen of a microcomputer. ${ }^{3} \mathrm{~A}$ joystick was connected to the computer's I/O port, and the audio track containing the annunciator's spike was connected to the input port of the computer's timing card. The user watched the superimposed image of the cursor and the subject while manipulating the joystick to keep the cursor superimposed

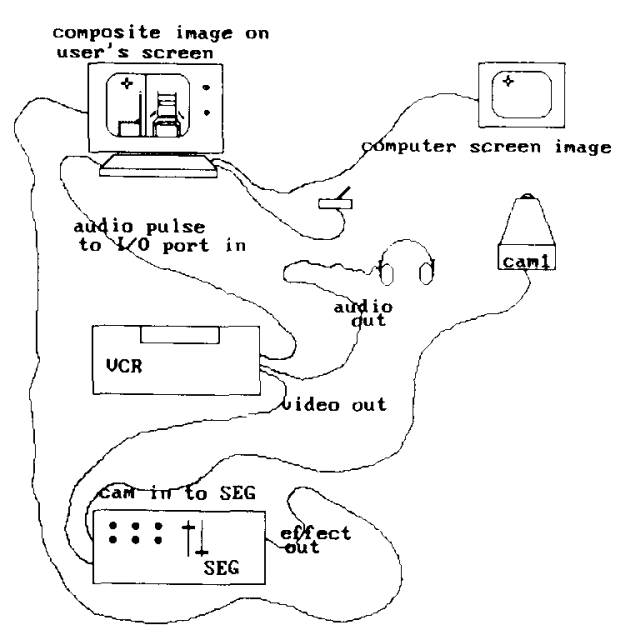

Figure 2. Equipment configuration for measuring motion. 
on the center of the subject's hand; the cursor appeared directly over the target of interest, with both cursor and target being projected simultaneously on the monitor's raster. Digitizing was done in real-time, first for the front view and then for the side view, the videotape being rewound to the start of the narrative between these two passes. The microcomputer coordinated the time bases of the two analyses by using the voltage spike from the annunciator as a temporal reference point: a datacollection routine in the software was activated when the first spike was encountered, and it was turned off when the second spike was encountered. Because both views shared a common time base established by the computer's timer, $x-y$-coordinates taken from the front view every $n$ milliseconds could be associated with $x$-, $y$-coordinates taken from the side view at similar intervals. Specifically, the side view's $x$-coordinates became labeled as $z$-coordinate data and were concatenated with $x, y$ data from the front view. Raw measurements were converted to standard metric units by videotaping a stable 3-dimensional object of known size. The ratio of this object's real size to its traced size provided a conversion constant that transformed the $x, y$ measurements from the computer into standard units. Measurements were formatted by the software so that any displacement equal to or greater than 1.5 in. occurring within $125 \mathrm{msec}$ was considered a discrete movement, or part of one. ${ }^{4}$ For each hand movement, the system furnished duration in seconds, linear displacement in inches, time of onset and termination, and velocity in inches per second (ips). The system also determined total displacement during the narrative, average velocity during the narrative, and total movement duration during the narrative.

The equipment was drawn from the components listed above, and also included a timing card from John Bell Engineering (JBE 6522 Parallel Interface), a joystick (Kraft Model D4), and an optimized compiled BASIC program (VIDEO INTERFACE) written specifically for this application. ${ }^{5}$

\section{RESULTS AND DISCUSSION}

To test interrater reliability of the system, two users independently traced the right hand of an active subject throughout one 70 -sec narrative chosen at random. ${ }^{6}$ Twenty-five blind independent measurements of the right hand's average velocity during this 70 -sec segment were made by each user. ${ }^{7}$ That is, each user traced the hand 50 times, a process yielding 25 measurements of the hand's average velocity in the $x, y, z$ dimensions during the narrative. The two grand means of these 25 repeated measurements were 10.24 and 9.83 ips $[t(48)=1.09$, $p<.20$, two-tailed, n.s.], suggesting no significant difference between users for absolute level of average velocity. Though such negative findings are not unequivocal evidence of reliability, the likelihood of a Type II error in this analysis is limited by the fact that the variances in the two samples are approximately equal $\left(s^{2}=1.11\right.$ and 1.20 , respectively, $F^{\prime}[24,24\}=1.08, p>.05$, n.s., two-tailed, where criterion value for $F^{\prime}$ at the .05 level is 1.98) and the statistical power of the test, .79 (Hays, 1981 , p. 252), reached recommended levels (Cohen \& Cohen, 1983). Interrater agreement was further assessed by correlating descriptive statistics for each discrete movement in the narrative, as specified in the first of each user's 25 measurements. The correlations between users were $r=.99, p<.0001$, for onset time of the six discrete gestures in this narrative; $r=.85, p<.03$, for their duration; $r=.89, p<.02$, for their extent; and $r=.90$, $p<.01$, for their velocity. These data are consistent with earlier work (Fersiew et ai., 1982) demonstrating high reliability (viz., Spearman-Brown coefficients of $.83, .80$, and .85 ) between subjects on computer-mediated tracking tasks.

Obtaining statistics on the system's validity is somewhat problematic, because it is not possible to provide standard gestures whose measurements are independently established. To test the "resolving power" of the system, a user made 25 independent measurements of a motorized target tracing a circle $75.4 \mathrm{in}$. in circumference. Differences between the mean observed value and the true value were $|.06|,|.06|$, and $|.30|$ in. in the $x, y$, and $z$ dimensions, respectively. The $95 \%$ confidence intervais for the $x$ and $y$ dimensions were \pm 1.3 and \pm 1.4 in., respectively. No confidence interval could be computed for the $z$ dimension because errors cannot be normally distributed on either side of a spatial value of zero, making a confidence interval inappropriate (Hays, 1981); theoretically, the $z$ dimension's confidence interval should be equivalent to that of the $x$ dimension because $z$ measurements are generated by tracking motion in the transverse plane of the side-view image. Though circles are harder to track than other regular figures (Griffith, Voloschin, Gibb, \& Bailey, 1983; Jensen, 1975), our data document the upper limit of the system's precision, given the fact that tracking accuracy is enhanced by practice (Ferslew, Manno, Manno, Hubbard, \& Vekovius, 1983; Griffith et al., 1983; Poulton, 1969), low velocity (Bradley, 1977; Griffith et al., 1983), predictability (Ferslew et al., 1982), and peripheral devices requiring fine-motor control (Ferslew et al., 1983).

To test the accuracy of Cartesian analysis in more realistic conditions, 80 gestures from the 221 narratives described above were examined independently by two judges (the first author and a research assistant), who made estimations of each gesture's duration and linear displacement; neither judge knew the estimations fumished by the other judge nor the measurements furnished by Cartesian analysis. ${ }^{8}$ The correlation between estimated length (averaged across the two judges) and measured extent was $r(80)=.73, p<.0001$; and the correlation between estimated duration (as assessed from frame-byframe inspection of the videotape) and measured duration was $r(80)=.80, p<.0001$. The correlation be- 
tween estimated length and measured length suggests a reasonable degree of accuracy, though interpretation of the correlation is impeded by the fact that linear displacement is increasingly underestimated as velocity increases (Bradley \& Godiksen, 1984). Interpreting the correlation between measured duration and estimated duration is more straightforward. The relatively high coefficient suggests good validity, and it is consistent with previous research on eye-hand coordination where percentage of time-ontarget in pursuit rotor tasks is approximately $80 \%$ for inexperienced users (Griffith et al., 1983; but see Kohl, Roenker, \& Indermill, 1987).

When taken as a whole, the results suggest that the interface can provide measurements with a reasonable degree of accuracy and reliability, though accuracy will of course be a function of numerous features (e.g., camera resolution, the user's tracking ability, the size of the cameras' field of view in the veridical three-dimensional world) that will vary with each application. Because precision will necessarily decline as the complexity of the visual display and the unpredictability of the movement increase (Ward \& Chien, 1980), videotapes containing highly erratic motion may require previewing before measurement begins, and extremely fast motion (at and above approximately $40 \mathrm{deg} / \mathrm{sec}$ ) will not be especially amenable to real-time tracking (Bradley, 1977) with this interface. However, slow-motion playback of the videotape during tracking could accommodate such situations, provided that measures of duration and velocity were multiplied by an appropriate value. It should be noted that a real-time analysis was possible with this interface in a set of studies examining the relation between gestures and the spontaneous speech that accompanies them (MorrelSamuels, 1989). It could also be used to furnish quantitative measures of motion in studies where subjects' perceptions of meaning, form, and function are of interest. The method promises to be especially suitable in studies where naturalism must be maintained and physical contact with the moving body is not possible.

\section{REFERENCES}

Atkinson, M. L., \& Allen, V. L. (1983). Perceived structure of nonverbal behavior. Journal of Personality \& Social Psychology, 45, 458-463.

Barnes, H. J., Vaughan, J., Jorgensen, M. J., \& Rosenbaum, D. A. (1989). A low-cost method for digitizing videotaped continuous movements on the Macintosh. Behavior Research Methods, Instruments, \& Computers, 21, 255-258.

BECK, C. (1988). Norm setting for the verbal estimation of a 40 -second interval by women of childbearing age. Perceptual \& Motor Skills, 67, 577-578.

BRADLEY, D. R. (1977). The apparent size of the path traversed by a rotating target during saccadic and smooth pursuit: New data on the shrinking circle illusion. Perception \& Psychophysics, 22, 183-190.

Bradley, D. R., \& Godiksen, E. B. (1984). The "shrinking circle illusion" is a shrinking ellipse. Perception, 13, 207-212.

BuCK, R., Baron, R., \& Barrette, D. (1982). Temporal organization of spontaneous emotional expression: A segmentation analysis. Journal of Personality \& Social Psychology, 42, 506-517.
Cavallo, V., \& Laurent, M. (1988). Visual information and skill level in time-to-collision estimation. Perception, 17, 623-632.

COHEN, J., \& COHEN, P. (1983). Applied multiple regression/correlation analysis for the behavioral sciences (2nd ed.). Hillsdale. NJ: Erlbaum.

DAPENA, J. (1978). Three-dimensional cinematography with horizontally panning cameras. Sciences et Motricite, 1, 3-15.

Diersen, G., Lorenc, L., SPIraleri, R. (1961). A new method for graphic study of human movements. Neurology, 11, 610-616.

Dowd, J. M., \& TroNiCK, E. Z. (1986). Temporal coordination of arm movements in early infancy: Do infants move in synchrony with adult speech? Child Development, 57, 762-776.

EkMAN, P., Fruesen, W. (1972). Hand movements. Journal of Communication, 22, 353-375.

EshKol, N., WachmanN, A. (1958). Movement notation. London: Weidenfeld \& Nicolson.

Ferslew, K. E., Manno, J., Manno, B., Hubbard, J., \& Vekovius, W. A. (1983). Determination of fine and coarse pursuit-tracking performance. Perceptual \& Motor Skills, 56, 683-690.

Ferslew, K. E., Manno, J., Manno, B., Vekovius, W. A., HubBARD, J., \& Bairnsfather, L. (1982). Pursuit Meter II: A computerbased device for testing pursuit-tracking performance. Perceptual \& Motor Skills, 54, 779-784.

Futrelle, R., \& Potel, M. J. (1975). The system design for GALATEA, an interactive real-time computer graphics system for movie and video analysis. Computer \& Graphics, 1, 115-121

Griffith, J. L., Voloschin, P., GiBB, G. D., Balley, J. R. (1983). Differences in eye-hand motor coordination of video-game users and non-users. Perceptual \& Motor Skills, 57, 155-158.

Hays, W. (1981). Statistics (3rd ed.). New York: Holt, Rinehart \& Winston.

Hofsten, C. von (1979). Development of visually directed reaching: The approach phase. Joumal of Human Movement Studies, 5, 160-178.

Horsten, C. von (1980). Predictive reaching for moving objects by human infants. Journal of Experimental Child Psychology, 30, 369-382

Hutchinson, A. (1970). Labanotation. New York: Theatre Arts Books.

JENSEN, B. E. (1975). Pre-task speed training and movement complexity, or factors in rotary pursuit skill acquisition. Research Quarterly, 46, 1-11.

JoUEN, F., \& LEPECQ, J.-C. (1989). Optical and electronic systems for spatial and temporal analysis of video images. Behavior Research Methods, Instruments, \& Computers, 21, 2-10.

Kohl, R. M., Roenker, D. L., Indermill, C. (1987). Scaling task complexity along a single dimension. Perceptual \& Motor Skills, 65 , 463-467.

Krauss, R. M., Morrel-Samuels, P., \& Hochberg, J. (1988). VIDEOLOGGER: A computerized multichannel event recorder for analyzing videotapes. Behavior Research Methods, Instruments, \& Computers, 20, 37-40.

LABAN, R. (1974). The language of movement. Boston: Plays.

LIEN, D. (1986). The BASIC handbook: An encyclopedia of the BASIC language (3rd ed.). San Diego: Compusoft.

Mackay, S., Potel, M. J., \& Rubin, J. (1982). Graphics methods for tracking three-dimensional heart wall motion. Computer Biomedical Research, 15, 455-473.

MORREL-SAMUELS, P. (1980). Recording and analyzing human movement. Unpublished MA thesis, University of Chicago.

MorRel-Samuels, P. (1989). Gesture word and meaning: The role of gesture in speech production and comprehension. Unpublished $\mathrm{PhD}$ dissertation, Columbia University.

Morris, R. B., \& RULE, S. J. (1988). Sequential judgement effects in magnitude estimation. Canadian Journal of Psychology, 42, 69-77.

Munteanu, I., \& Latcu, A. (1971). Folclor coregrafic din vaille timisului si bistrei. Bucharest: Restia.

Nakajima, Y., Nishimura, S., \& Teranishi, R. (1988). Ratio judgements of empty durations with numeric scales. Perception, 17, 93-118.

NEWTSON, D. (1973). Attribution and the unit of perception of ongoing behavior. Journal of Personality \& Social Psychology, 28, 28-38.

Newtson, D., Engquist, G. A., \& Bois, J. (1977). The objective basis 
of behavior units. Journal of Personality \& Social Psychology, 35 , 847-862.

Pearson, J., McGinley, D., \& Butzel, L. (1963). A dynamic analysis of the upper extremity: Planar motion. Human Factors, 5, 59-70.

Poizner, H., Klima, E. S., Bellugi, U., \& Livingston, R. B. (1986). Motion analysis of grammatical processes in a visual-gestural language. In V. McCabe \& J. Balzano (Eds.). Event cognition: An ecological perspective (pp. 155-174). Hillsdale, NJ: Erlbaum.

Polzner, H., Wooten, E., \& Salot, D. (1986). Compulergraphic modeling and analysis; A portable system for tracking arm movements in three-dimensional space. Behavior Research Methods, Instruments, \& Computers, 18, 427-433.

Potel, M. J., \& SAYRe, R. (1976). Interacting with the GALATEA film analysis system. Computer Graphics, 10, 52-59.

Potel, M. J., Sayre, R., \& Robertson, A. (1979). A system for interactive film analysis. Computers \& Biological Medicine, 9, 237-256.

Poulton, E. (1969). Tracking. In E. Bilodeau (Ed.), Principles of skill acquisition (pp. 287-318). New York: Academic Press.

SHOLL, M. J. (1989). The relation between horizontally and rod-andframe and vestibular navigational performance. Joumal of Experimental Psychology: Learning, Memory, \& Cognition, 15, 110-125.

SwANSON, J., TAYLOR, D. L. (1982). Local and spatially coordinated movements in Dictyostelium discoideum amoebae during chemotaxis. Cell, 28, 225-232.

Thomas, H. J Jamison, W. (1975). On the acquisition of understanding that still water is horizontal. Merrill-Palmer Quarterly, 21, 31-44.

TrochIm, W. M. K. (1976). The three-dimensional graphic method for quantifying body position. Behavior Research Methads \& Instrumentation, 8, 1-4.

WARD, M., CHIEN, Y. (1980). Analysis of time-varying imagery through the representation of position and shape changes. Proceedings of the Fifth International Conference on Pattern Recognition, 2, 1236-1238.

\section{NOTES}

1. The Selspot Movement Monitoring System is available from Selcom, Box 4032, S-433 04 Partille, Sweden.

2. The Peak 3D Motion Measurement Module is available from Peak Performance Technologies, Inc., 7388 S. Revere Parkway, Suite 601, Englewood, CO 80112 (TEL: 303 799-8686). Approximate cost of the system is $\$ 48,000$.
3. The cursor was restricted to a rectangular area in the central portion of the computer monitor, with the camera-located $18 \mathrm{ft}$ awayfocusing in on the rectangle to minimize nonlinearity and parallax associated with curvature of the monitor's screen. For similar reasons, the narratives were recorded with a relatively large field of view, so that the subjects' hands would rarely occupy the screen's periphery.

4. This criterion was arbitrary, and represented a balance between the need to differentiale distinct movements in this study, the desire for high temporal resolution (i.e., with $x$-, $y$-, $z$-coordinates being taken at relatively short intervals), and the constraint imposed by the microcomputer's limited memory. The program is written so that users are prompted to set both the temporal and the spatial values of this criterion before each analysis.

5. Although this code was written for an Apple computer, the software could easily be adapted for IBM-compatible machines (Lien, 1986). An uncompiled unoptimized version of the programs can be furnished on request to those interested in making such a conversion.

6. The subject was selected because she appeared to be in the upper quarter of our subject sample for gesture velocity and gesture size as well as number of gestures produced; subsequent measurement of all 221 narratives in the experimental corpus confirmed that she met or surpassed this criterion.

7. Both users (the first author and a research assistant) had minimal experience with the interface and the narratives before this test, though both had been present at the videotaping several months earlier, and each had previously viewed the narratives from all subjects during the selection process described above. Neither user had any experience tracking gestures with the interface.

8. The 80 gestures were selected in a separate procedure: groups of subjects viewed all the narratives and used their own criteria to identify speech-related gestures. One hundred and ninety-three gestures were identified by at least 8 out of 10 viewers. Eighty of these gestures met the criteria of being fully measured and unilateral. Specifically, the final sample excluded all two-handed gestures, gestures that continued after the narrative's termination, gestures whose measurements merged with those of a preceding or subsequent self-touching motion (Ekman \& Friesen, 1972), gestures containing a moment of inactivity long enough to require formatting as two distinct motions, and gestures that traveled out of the cameras' fields of view.

(Manuscript received April 27, 1990; revision accepted for publication August 20, 1990. 